ARTIKEL

\title{
EFESIENSI BIAYA TRANSAKSI DALAM PENYESUAIAN PENETAPAN TARIF BARU: STUDI STRATEGI BERSAING GOJEK TERHADAP REGULASI BARU DAN BERTAHAN DI ERA PANDEMIK COVID 19
}

\author{
Adi Setiadi \\ Mahasiswa Pascasarjana Universitas Padjajaran \\ Email: adi20001@mail.unpad.ac.id
}

\begin{abstract}
Abstrak
Tujuan penelitian ini adalah untuk mengetahui strategi yang digunakan Gojek dalam upaya bersaing di era pandemik Covid-19 dan penetapan regulasi oleh pemerintah tentang tarif baru. Batasan penelitian ini terbatas pada biaya transaksi yang mucul untuk memperoleh informasi data konsumen dengan melakukan proses periklanan dan jenis produk terbatas pada barang private (private goods) layanan gojek pada goride. Metode penelitian menggunakan metode penelitian kualitatif-deskriptif dengan studi literatur. Penelitian ini menghasilkan bahwa peluncuran GoScreen yang dilakukan Gojek dalam mengefesiensi biaya pemenuhan informasi data sangat efektif untuk dapat bersaing dan GoScreen berdampak sosial dalam membantu para mitra Gojek untuk menambah penghasilan $20 \%$ dari pendapatan normalnya.
\end{abstract}

Kata Kunci: Biaya Transaksi, Tarif baru, Gojek.

\begin{abstract}
The purpose of this study was to determine the strategies used by Gojek in an effort to compete in the Covid-19 pandemic era and to determine regulations by the government regarding new tariffs. The limitations of this study are limited to the transaction costs that appear to obtain consumer data information by carrying out the advertising process and the types of products are limited to private goods (private goods), Gojek services at Goride. The research method uses qualitative-descriptive research methods with literature studies. This research resulted in the launching of GoScreen which was carried out by Gojek in making the cost of fulfilling data information very effective in order to compete and GoScreen having a social impact in helping Gojek partners to increase their income by $20 \%$ of their normal income.
\end{abstract}

Keywords: Transaction Fees, New Rates, Gojek.

\section{A. PENDAHULUAN}

Era Vuca yang sedang kita alami saat ini memberikan efek terhadap disrupsi yang sangat cepat terhadap berbagai aspek khususnya ekonomi. Ekonomi adalah salah satu aspek utama yang selalu menghadapi efek langsung atas segala aktivitas perubahan. Seperti yang dijelaskan sebelumnya pada perubahan globalisasi, revolusi industri, perang dagang dan kondisi pandemi. Setiap regulasi yang dimunculkan selalu mengutamakan kepentingan ekonomi daripada aspek lainnya. Hal ini dilakukan karena ekonomi adalah bagian terpenting 
ARTIKEL

yang harus dibenahi dan selanjutnya dengan harapan akan berpengaruh langsung terhadap aspek lain. Komplikasi era yang dialami saat ini berpengaruh terhadap fenomena bisnis melalui berbagai perilaku kebiasaan baru para masyarakat konsumen. Disebabkan oleh berbagai regulasi dari pemerintah atas upaya mencegah bertambahnya korban baru atas Coronavirus 2019. Menjadikan masyarakat melakukan berbagai kebiasaan baru dan pelaku bisnis memaksakan diri harus melakukan inovasi terhadap berbagai aspek yang sedang terdisrupsi oleh komplikasi era yang terjadi.

Konsep Ekonomi dan politik berperan penting dalam upaya mendampingi kelembagaan bisnis dan masyarakat konsumen untuk saling mendukung untuk keseimbangan perekonomian. Pemerintah dalam upayanya memiliki kuasa dalam sistem hukum dan kebijakan untuk menyesuaikan terhadap perubahan industri. Seperti yang sedang hangat sekarang adanya paket perundangan Omibus Law yang sudah disahkan dan ditandatangan oleh pemerintah yang diiringi serangkaian demonstrasi pro dan kontra ditengah masyarakat. Pro dan kontra yang terjadi merupakan hasil buruknya komunikasi dan kurangnya pengetahuan tentang isi

kontekstual Omnibus Law tersebut. Sehingga menimbulkan keraguan di tengah masyarakat terhadap paket perundangan tersebut. Bagi sebagian pelaku bisnis pada lini bisnis tertentu tidak mendukung adanya Omni bus Law tersebut. Maka perlu adanya media penyampaian informasi mengenai paket kebijakan tersebut sebelum disahkan. Sebagai contoh interpensi penetapan tarif ojek online, penggunaan TV digital dari TV analog dan berbagai rencana regulasi yang akan dilakukan. Maka dibutuhkan media komunikasi yang tepat agar produk tersebut sampai kepada konsumen dan diterima dengan baik, tentunya mengharapkan feedback yang baik pula. Ekonomi politik media komunikasi sangat berperan agar setiap kebijakan dan perubahan strategi bisnis kelembagaan dapat sampai dan dipahami oleh penggunanya yakni masyarakat konsumen. Secara teori menurut Mosco (2009) dalam (Wahyuono, 2019:130) menjelaskan bahwa pemerintah memiliki peran terhadap perubahan struktur industri dan perusahaan media. Menurut Mosco (1996) mengkategorikan ekonomi politik media menjadi tiga bagian fondasi. Fondasi ini sering juga disebut sebagai pintu masuk dalam memahami konsep ekonomi politik Mosco. Pintu masuk ini diantaranya ialah, komodifikasi, strukturasi dan spasialisasi. Berbagai lembaga bisnis saling berupaya menciptakan ide, strategi dan taktik bisnis agar dapat bertahan tidak hanya dari komplikasi era yang dialami tetapi harus mampu bertahan dari berbagai kompetitor yang juga mempunyai motivasi yang sama untuk dapat bertahan di era komplikasi saat ini. Taktik 
ARTIKEL

adalah merupakan bagian dari strategi pemasaran yang pada konsep marketing saat ini menurut Kotler dan Kartajaya telah mengalami disrupsi yang semula taktik marketing mix yang terdiri dari produck, price, place dan promotion telah bergeser ke konsep crowd combo yang terdiri dari co-creation, currency, communal activation, communication (Darwin, 2020). Pada konsep biaya transaksi misalnya, price pada konsep lama telah berubah menjadi currency yang mana harga telah bergeser menjadi tidak tetap dan serupa dengan mata uang (currency) (Kotler et al., 2019). Mata uang memiliki karekter yang berubah, maka price model terkini juga tidak memiliki penentuan harga yang tetap tetapi berubah-ubah menyesuaikan kebutuhan pasar dan konsumen. Karena era saat ini segala aspek bisnis harus berasal dari pasar/konsumen bukan lagi berasal dari perusahaan. Biaya transaksi yang muncul untuk menentukan harga juga harus dapat disesuaikan dengan keinginan pasar dan konsumen.

Bagi pelaku bisnis sturtup seperti gojek misalanya, biaya transaksi saat ini sangat diperhatikan tidak hanya memperhitungkan kecocokan tarif yang sesuai dengan konsumen dan kompetitor, tetapi ada beberapa biaya transaksi yang diperhitungkan seperti biaya mencari informasi data konsumen, biaya monitoring atas uapaya mempertahankan kualitas pelayanan, biaya adaptasi atas perubahan yang terjadi dan tentunya biaya untuk kenotarisan atas berbagai ijin regulasi pemerintah. Biaya-biaya transaksi ini muncul akibat dari berbagai ketidakpastian yang sedang terjadi saat ini yang mulai dari kondisi perekonomian global dan resesi yang sedang dialami dan kondisi pandemik. Tentunya Gojek harus mampu memberikan keseimbangan harga yang timbul dari berbagai biaya-biaya transaksi yang dikeluarkan agar bisnis dapat bertahan dan masyarakat dapat dilayani dengan baik. Ada beberapa upaya Gojek dalam mengatasi pembengkakan biaya transaksi akibat penetapan regulasi pemerintah tentang tarif dan akibat kondisi pandemik covid 19. Misalnya dalam penggunaan biaya periklanan. Biaya iklan merupakan usaha dalam mendapatkan informasi data perilaku konsumen terhadap pelayanan Gojek. Biaya untuk mencari data informasi konsumen melalui periklanan sangatlah efektif pada era digitalisasi saat ini. Karena banyak cara yang dilakukan dengan biaya yang sangat murah bahkan tidak mengeluarkan dana (Kartajaya, 2019). Contohnya dengan iklan melalui media sosial yang mana setiap orang membicarakan produk yang dipasarkan. Jika produk yang ditawarkan memiliki peran yang sangat memuaskan dirasakan para konsumen dengan sendirinya mereka akan meng-advocacy produk tersebut. Sehingga valesi percakapan di media sosial semakin positif yang kemudian akan memberikan brand image yang baik dimata konsumen juga sebaliknya. Maka dalam hal kompotitor ingin menetapkan tarif yang lebih murah, konsumen itu sendirilah yang meng- 
ARTIKEL

advocacy brand kepada konsumen lain bahwa dengan tarif tersebut konsumen sudah mendapatkan layanan yang sangat memuaskan tanpa mencari tarif yang lebih murah yang tidak masuk akal.

Biaya transaksi atas memperoleh data informasi produk bertujuan untuk dapat menentukan strategi dan taktik bisnis yang harus dilakukan dalam menghadapi kompotitor dalam upaya menyesuaikan regulasi penerintah di masa pendemik. Iklan sangat dibutuhkan untuk memyampaikan berbagai informasi tidak hanya kepada konsumen juga kepada driver gojek. Pengaruh penetapan regulasi baru terhadap kenaikan tarif dimasa pandemik tentunya sangat berpengaruh terhadap pendapatan driver gojek juga meningkatnya stress yang dialami (Hapsari et al., 2020). Tentunya untuk mengangkut orang tidak bisa maksimal lagi karena dibatasi oleh regulasi PSBB (sosial/physical distancing) dan konsumen juga akan merasa berpengaruh dengan kenaikan tarif yang mana pada masa pandemik sekarang kebanyak pekerja mendapatkan potongan pendapatan tiap bulan karena jam bekerja yang tidak maksimal (work from home). Sesuai dengan Peraturan Menteri Nomor 12 Tahun 2019 pada pasal 11 poin 5 tentang pedoman perhitungan biaya jasa. Untuk mengadaptasi keputusan tersebut, Dirjen Perhubungan menkenaikkan tarif ojek online yang merupakan hasil evaluasi bersama YLKI (Yayasan Lembaga Konsumen Indonesia) dengan melakukan survei dari 13 sampai 17 Februari 2020 kepada 1.862 responden (https://www.cnbcindonesia.com). Berikut ini tarif baru ojek online yang diperoleh dari sumber kompas : 


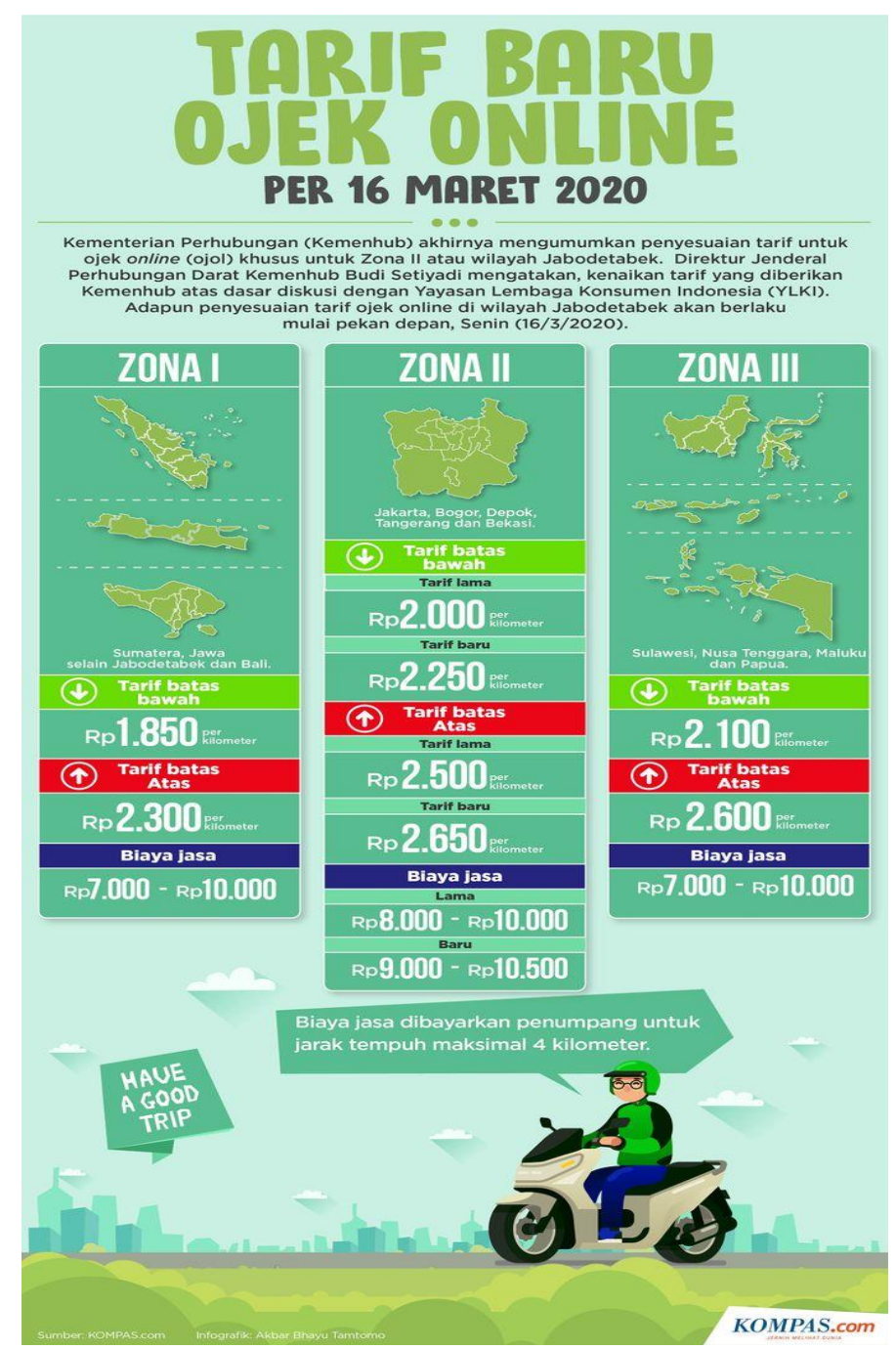

Gambar: Tarif Baru Ojek Online Berlaku dimasa Pandemi

Berikut ini data survei yang dilakukan APJII (Asosiasi Penyelenggara Jasa Internet Indonesia) melalui kuesioner dan wawancara terhadapa 7.000 sampel pada kuartal II tahun 2020 tentang jasa transportasi online yang sering digunakan. Ada 21,3\% responden mengaku sering menggunakan aplikasi Grab. 19,4\% menggunakan apikasi Gojek dan sisanya menggunakan aplikasi kompetitor lain. 


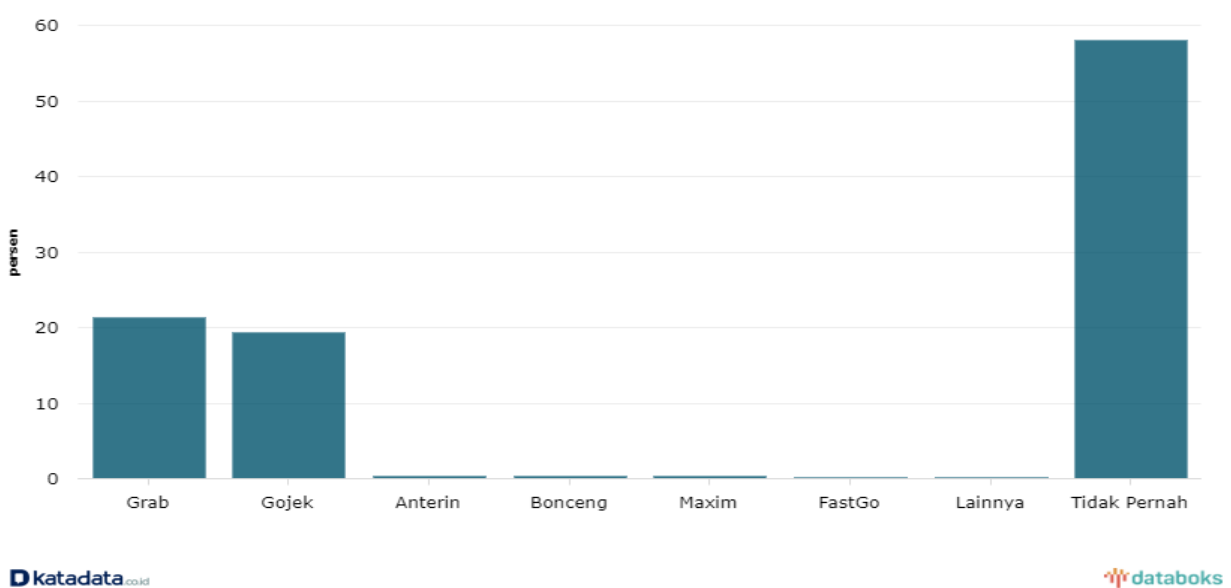

\section{Gambar: Diagram Jasa Transportasi Online Paling Sering Digunakan}

Dari gambar diagram diatas terlihart bahwa aplikasi Gojek masih berada dibawah aplikasi Grab. Hal inilah yang harus diatasi oleh Gojek agar bisa kembali mengungguli Grab degan berbagai strategi dan taktik. Tentunya dengan cara yang tidak mengeluarkan biaya yang besar agar biaya transaksi dapat dikontrol dengan baik untuk dapat menemukan tarif yang cocok untuk diterapkan mengaplikasi peraturan Dirjen Dithub yang baru.

Dari berbagai fenomena bisnis diatas dan berbagai reaserch dan theory gap yang diuraiakan ditemukan masalah bahwa; bagaimanakah Gojek mengefesiensi biaya transaksi yang timbul dalam upaya menyesuaikan tarif baru ditengah masa pandemi dan mengaplikasi regulasi pemerintah. Pembatasan pada penelitian ini adalah terbatas pada biaya transaksi yang mucul untuk memperoleh informasi data konsumen dengan melakukan proses periklanan dan jenis produk terbatas pada barang private (provate goods) layanan gojek pada goride.

\section{B. KAJIAN PUSTAKA}

\section{Gojek (PT. Aplikasi Karya Anak Bangsa)}

Dikutip dari laman wikipedia (https://id.wikipedia.org/wiki/Gojek), Gojek (sebelumnya ditulis GO-JEK) merupakan sebuah perusahaan teknologi asal Indonesia yang melayani angkutan melalui jasa ojek. Perusahaan ini didirikan pada tahun 2010 di Jakarta oleh Nadiem Makarim. Saat ini, Gojek telah tersedia di 50 kota di Indonesia. Hingga bulan Juni 2016, aplikasi Gojek sudah diunduh sebanyak hampir 10 juta kali di Google Play pada sistem operasi Android, dan telah tersedia di App Store.

Fitur dan layanan gojek memiliki 24 layanan yang salah satunya adalah GoRide atau GET-Win GO-BIKE, layanan transportasi penumpang dengan sepeda motor (Tersedia di Indonesia, Thailand dan Vietnam). Layanan ini adalah salah satu layanan yang sangat 
ARTIKEL

berdampak akibat pandemik dan regulasi pemerintah terhadap kenaikan tarif baru. Alasannya adalah karena penerapan sosial/physical distancing. Adapun anak perusahaan yang dimiliki sebanyak 16 perusahaan dan termasuk didalamnya PT. Blue Bird Tbk.

\section{Ekonomi Politik}

Thostein Veblen (1857-1929) adalah seorang pakar ekonomi politik kelembagaan. Veblen menjelaskan bahwa kelembagaan yang membentuk sebuah norma yang membentuk perilaku masayarakat untuk bertindak produktif dan konsumtif. Dalam teorinya The Theory Of Leisure Class (1899) menggambarkan perilaku konsumtif masarakat Amerika yang tidak wajar (conspicius sonsumption) yakni yang materialistis yang tidak mengedepankan rasionalitas seperti teori Klasik dan Neoklasik.

Selanjutnya dalam bukunya Absentee Ownership and Business Enterprise (1923), membahas tentang perilaku produsen dalam mencari laba dengan usaha kerja keras namun pada saat ini dilakukan dengan berbagai trik dan taktik. Trik dan Taktik terkadang bisa berimplikasi licik yang berupaya mendapatkan lanba yang sebesar-besarnya dan berupaya mematikan kompotitornya. Oleh Vablen perilaku ini disebut dengan production for profit.

Menurut Murdock \& Golding dalam (Sanjaya, 2020, p. 33) menjelaskan bahwa kajian ekonomi politik kritis meliputi empat unsur pokok, yang terdiri dari holistik, historis, memusatkan perhatian pada keseimbangan antara perusahaan kapitalis dan intervensi publik, dan efisiensi di luar masalah teknis yang terkait dengan moral, keadilan dan barang publik. Secara historis ada lima aspek yang menjadi pusat kajian utama, yang terdiri dari: pertumbuhan media, perluasan jangkauan perusahaan, komodifikasi, universalisasi kewarganegaraan, dan perubahan peran negara dalam hal intervensi pemerintah. Kelima aspek ini saling memiliki keterkaitan satu sama lain.

Dalam hal komodifikasi menurut Mudrock dan Golding sejalan dengan teori Mosco (1996) mengkategorikan komodifikasi menjadi bagian fondasi ekonomi politik mosco (Wahyuono, 2019). Komodifikasi media merupakan upaya menjadikan pesan sebagai produk yang memiliki nilai jual dari berbagai elemen industri. Produksi pesan dan kreatif, distribusi, konsumsi bahkan sampai kepada konsumen dan produsennya. Bahkan dalam tahap yang lebih jauh pesan juga dapat dikomodifikasi dalam bentuk lain yang tetap memiliki nilai jual seperti merchandise atau produk sejenis terpisah. Dan strukturasi merupakan proses dimana struktur dibentuk oleh agen (human agency), sementara agen ini pun menjadi medium dari struktur yang dibentuk. 
Jenis Barang/Jasa

Dalam (Suwitri et al., 2005) mengemukakan ada tiga jenis barang dan jasa dalam ekonomi yaitu:

1. Murni barang publik (pure public goods). Barang atau jasa yang hanya boleh disediakan oleh pemerintah (pure public goods)

2. Murni barang privat (private goods), jenis barang ini penyediaannya sepenuhnya dikelola masyarakat (private goods)

3. Barang tool (tool goods) dan barang kolektif (Collective goods). Jenis ketiga ini penyediaannya bersifat Jenis penyediaannya bersifat campuran antara pemerintah dan masyarakat.

\section{Biaya Transaksi}

Menurut Furubotn \& Richter dalam (Setyanto \& Samudro, 2016) biaya transaksi adalah ongkos untuk menggunakan pasar (market transaction costs) dan biaya memakai hak untuk memberikan pesanan (orders) di dalam perusahaan (managerial transaction costs). Selanjutnya dalam Yustika (2013), biaya transaksi merupakan biaya-biaya untuk melakukan proses negosiasi, pengukuran, dan pertukaran. Pasar menunjukkan bila pertukaran ternyata tidak hanya memperhitungkan berapa biaya dihabiskan untuk memproduksi suatu barang, tetapi harus memperhitungkan berapa biaya yang harus dikeluarkan.

Ada beberapa biaya transaksi yang muncul seperti biaya mencari informasi data konsumen, biaya monitoring atas uapaya mempertahankan kualitas pelayanan, biaya adaptasi atas perubahan yang terjadi dan tentunya biaya untuk kenotarisan atas berbagai ijin regulasi pemerintah. Hal ini dilakukan, bertujuan untuk menyesuaikan perkembangan industri yang ada.

\section{Penetapan Harga}

Pada penelitian (Abadi, 2016) membagi metode penetapan harga 3 kategori :

1. Cost Based Pricing dan Mark Up Pricing. Harga diterapkan setelah menghitung biaya produksi dan pemasaran ditambah dengan jumlah tertentu sehingga dapat menutupi biaya-biaya langsung hingga overhead dan laba (Kurniawan, 2014).

2. Value Based Pricing. Mereka mendapatkan pelanggan setia karena menawarkan harga yang relatif rendah dan memberikan produk berkualitas tinggi

3. Competitive Based Pricing. Metode penetapan ini berorientasi pada kekuatan pasar, di mana harga jual dapat sama dengan produk pesaing, bisa lebih mahal atau lebih murah. Metode penetapan harga ini digunakan jika terjadi persaingan yang ketat dan produk tidak terlihat 
perbedaannya dengan produk pesaing dan adanya pasar oligopoli.Perusahaan akan menurunkan harga lebih murah dari produk pesaing jika pengecer bertujuan pada total penjualan dengan keuntungan relatif kecil (Sunyoto, 2014)

\section{METODE PENELITIAN}

Metode penelitan yang digunakan dalam penelitian ini adalah metode penelitian kualitatif deskriptif. Penelitian ini merupakan penelitian studi literatur yang digunakan untuk mendeskripsikan model strategi penerapan tarif dari Gojek dalam mengaplikasi regulasi pemerintah tentang kenaikan tarif dimasa pandemic Covid-19.

\section{PEMBAHASAN}

Dalam upaya Gojek mengaplikasikan peraturan pemerintah tentang menaikkan tarif ojek online. Gojek terus memberikan inovasi dan mencari solusi yang tepat agar perusahaan dapat bersaing dengan kompetitor dengan tidak membebankan tarif maksimal 20\% sesuai dengan batas yang diberikan pemerintah. Tentunya dengan menekan biaya transaksi yang muncul akibat dari penyesuaian kebiasaan baru yang sekarang sedang terjadi seperti kondisi pandemik. Salah satu biaya transaksi yang muncul adalah adanya upaya Gojek dalam memperoleh informasi data tentang konsumen, memperoleh data tentang kondisi pengemudi gojek dan informasi-informasi lainnya yang dibutuhkan untuk mengambil keputusan bisnis dimasa pandemik dengan menyesuaikan tarif yang baru yang tepat.

Dalam upaya mendapatkan semua data yang diinginkan tentunya dilakukan dengan menggunakan periklanan. Periklanan dapat memberikan daya ukur terhadap perilaku konsumen dan memberikan pengaruh langsung terhadap minat beli konsumen dengan berbagai komodifikasi yang ditawarkan. Namun dalam menerapkan iklan untuk menggenjot penjualan dan dapat bersaing dengan kompotitor lainnya tentunya akan mengeluakan biaya. Ada beberapa upaya yang dilakukan dalam mengefesiensi biaya pada era konektifitas sekarang seperti teori yang dikemukakan Hermawan dan Kotler. Bahwa biaya iklan dapat diefesiensi dengan melibatkan konsumen meng-advocacy produk (Kartajaya, 2019) dan atau menggunakan cara lain yang bisa bermanfaat bagi produsen juga pengguna layanan (driver).

Dikutip dari laman resmi gojek tanggal 9 Nopember 2020 lalu (https://www.gojek.com),Super App terdepan di Asia Tenggara melalui lengan bisnisnya di bidang periklanan, Promogo resmi memperkenalkan GoScreen sebagai media iklan luar ruang (Out of Home/OOH) dengan teknologi terkini sehingga membuat iklan lebih efektif, 
ARTIKEL

optimal, dan tepat sasaran. Sebagai media OOH modern, GoScreen memiliki empat keunggulan dibandingkan dengan media sejenis yakni:

1. Teknologi iklan terprogram (programmatic ads) untuk personalisasi konten sesuai waktu dan lokasi audiens

2. Pengukuran impresi secara real-time

3. Memanfaatkan armada roda dua Gojek yang memiliki mobilitas tinggi dan jangkauan luas

4. Harga yang terjangkau.

Diungkapkan oleh Chief Commercial Officer Gojek, Antonie de Carbonel, bahwa GoScreen adalah merupakan teknologi yang dapat menjawab tantangan sekarang ini. GoScreen mampu mengukur kinerja periklanan berdasarkan loksi dan waktu secara lengkap. Selain itu GoScreen juga memberikan dampak sosial yang positif bagi mitra bisnis dan pengemudi dalam ekosistemnya. Sehingga pengemudi goride akan mendapatkan tambahan penghasilan dari Goscreen tersebut. Tentunya akan berdampak untuk membantu para pengemudi mengalami kesulitan dimasa pandemik dan diperkirakan mendapatkan peluang penghasilan tambahan sebesar $20 \%$ dari pendapatan normalnya.

Inovasi terbaru dari Promogo ini dipercaya mendapat antusiasme tinggi dari pengiklan, mengingat inovasi ini termasuk salah satu dari 12 tren teknologi periklanan yang telah dan akan terus berkembang. Apalagi, belanja iklan Indonesia di penghujung 2020 diperkirakan tetap tumbuh hingga 5,3\%. Tren positif industri periklanan di dalam negeri tercermin pada bisnis Promogo yang juga menunjukkan performa positif dalam dua tahun terakhir. Hingga kuartal tiga tahun 2020, secara rata-rata, seluruh solusi OOH dari Promogo mengalami peningkatan pertumbuhan bisnis (growth) sebesar 40\%, dengan lebih dari 50 ribu mitra driver tergabung, dan menghasilkan impresi sebesar 15 miliar kali penayangan.

Impelementasi teori pada ekonomi politik yang dilakukan oleh Gojek ini adalah sudah mencerminkan taktik bersaing yang positif. Strategi yang dikembangkan ini tidak hanya memiliki pengaruh langsung terhadap kinerja perusahaan untuk memperoleh laba, tetapi memiliki dampak sosial terhadap berbagai mitra Gojek bahkan mitra UMKM yang bisa memanfaatkan GoScreen. Dengan sambutan yang baik oleh masyarakat konsumen akan menghasilkan brand Image yang memposisikan Gojek sebagai layanan ojek online yang tidak hanya memntingkan laba tetapi berdampak sosial kepada masyarakat dengan memberikan kesempatn untuk bermitra. Tujuan berikutnya adalah ketika brand Gojek berhadapan dengan kompotitor, mitra dan konsumen itulah yang meng-advocacy brand 
ARTIKEL

tersebut kepada orang lain agar merekomendasikan gojek sebagai moda transportasi online yang terpercaya. Peran mitra dan Konsumen disini adalah sebagai influencer untuk menciptakan word of mout yang positif.

Sedangkan untuk implementasi pada pengefesiensian biaya transaksi dalam upaya memberikan tarif yang baru. GoScreen adalah merupakan jawaban yang tepat. Biaya transaksi periklanan GoScreen lebih murah daripada periklanan lainnya dan lebih tepat dan terukur. Sehinga ketika Gojek menerapkan batas tarif yang diatur dalam peraturan Dirjen Perhubungan yang dimulai tanggal 16 Maret 2020 lalu. Gojek mampu menghadirkan rasa nyaman kepada berbagai mitra dan pengemudi untuk dapat ikut dalam periklanan GoScreen sebagai upaya menambah penghasilan mereka. Gojek juga dapat menekan tarif baru lebih murah dengan kompotitor terdekatnya yakni Grabike dengan mampu memberikan promo potongan Rp.5.000,- bagi pemakai apikasi goride, lebih murah dari promo yang diberikan Grabike diangka Rp.4.000,-.

Gojek memiliki tarif sebesar 12.000 rupiah untuk perjalanan 1-10KM. Jika melakukan perjalanan 11-15 Km maka Gojek akan mematok tarif sebesar 15.000 rupiah. Jika melakukan lebih dari $15 \mathrm{KM}$ maka Gojek akan menambahkan biaya tambahan sebesar 2.000 rupiah per satu kilometernya. Tarif tersebut berlaku pada jam-jam biasa dan bukan pada jam sibuk, jika pada saat jam sibuk (rush hour) maka akan ada biaya yang berbeda. Untuk di jam sibuk kamu akan dikenakan biaya tambahan sebesar 5.000 rupiah artinya kamu akan membayar tarif lebih mahal dibandingkan pada saat jam-jam biasa. Jam sibuk yakni pada pagi hari dari jam 06.0009.00 dan sore 16.00-19.00. Sedangkan untuk Grabike, 1.750 per KM untuk 12 KM pertama, di atas $12 \mathrm{KM}$ ada penambahan 3.000 rupiah per-KM dan biaya tambahan pada jam sibuk sebesar 2.500. Kesimpulannya Gojek mampu menekan tarif lebih murah daripada Grab.

\section{E. KESIMPULAN}

Media luar ruang-Out Of Home $(\mathrm{OOH})$ Gojek dalam periklanan yang dikenalkan bernama GoScreen adalah merupakan taktik Gojek dalam menjawab berbagai perubahan yang terjadi saat ini. Mulai dari perubahan kebiasaan baru akibat masa pandemi Covid 19 juga akibat dari penerapan kenaikan tarif baru oleh pemerintah. Disamping berdampak secara langsung terhadap laba perusahaan juga berdampak secara sosial kepada para mitra gojek juga UMKM. Pengefesiensian biaya transaksi lebih efektif, karena pada biaya transaksi periklanan dalam upaya memperoleh data konsumen dengan model media luar ruang-Out $O f$ 
ARTIKEL

$\overline{\text { Home }(\mathrm{OOH}) \text { pada GoSreen mampu menekan biaya lebih murah daripada media periklanan }}$ lainnya.

\section{DAFTAR PUSTAKA}

Abadi, L. Y. (2016). EVALUASI STRATEGI PENETAPAN HARGA JUAL DALAM BISNIS GOURMET LAND CAFE. PERFORMA: Jurnal Manajemen Dan Start-Up Bisnis, 1(Penetapan harga), 112-117.

Darwin, M. (2020). THE EFFECT OF COMMUNICATION STRATEGY IN MARKETING 4.0 PURCHASE DECISION THROUGH BRAND ADVOCACY IN SHOPEE ECOMMERCE. Http://Journal.Stiemb.Ac.Id/Index.Php/Mea/Article/View/482， 4(2), 375-396. http://journal.stiemb.ac.id/index.php/mea/article/view/482

Hapsari, V. C., Sovitriana, R., \& Santosa, A. D. (2020). STRESS PADA PENGEMUDI OJEK ONLINE DI PANDEMIC COVID-19 MASA NEW NORMAL DI JAKARTA. Jurnal IKRA-ITH Humaniora, 5(Pandemik Covid 19), 29-38.

Kartajaya, H. (2019). Citizen 4.0 : Menjejakkan Prinsip-Prinsip Pemasaran Humanis Di Era Digital (Tarigan Andi (ed.)). Gramdeia Pustaka Utama.

Kotler, P., Kartajaya, H., \& Setiawan, I. (2019). Marketing 4.0 : Bergerak dari Tradisional ke Digital (A. Tarigan (ed.)). Gramedia Pustaka Utama.

Sanjaya, M. (2020). PRAKTIK EKONOMI POLITIK MEDIA PADA TAYANGAN LIGA INGGRIS DI TVRI. Jurnal Ilmu Komunikasi Politik Dan Komunikasi Bisnis, 4 (1)(Ekonomi Politik Media), 30-39.

Setyanto, A. R., \& Samudro, B. R. (2016). KAJIAN DETERMINAN BIAYA TRANSAKSI TAKSI KONVENSIONAL DENGAN BIAYA TRANSAKSI TAKSI ONLINE. Semnas Fekon UT, Biaya Transaksi, 514-527.

Suwitri, S., Rachyuningsih, E., \& Sasmito, C. (2005). PELAYANAN PUBLIK : PUBLICPRIVATE PARTNERSHIP PERCEPATAN INFRASTRUKTUR DI INDONESIA 2005-2009. JIAKP, 2(Pelayan publik), 961-978.

Wahyuono, J. A. (2019). EKONOMI POLITIK PENGEMBANG GAME LOKAL Spasialisasi dan Ekspansi Bisnis PT Git Solution dan Noobzilla di Yogyakarta. Journal Communication Spectrum, 9 (2)(Ekonomi Politik), 125-142. https://doi.org/http://dx.doi.org/10.36782/jcs.v9i2.1954

https://www.cnbcindonesia.com/tech/20200316061757-37-145021/hari-ini-tarif-baru-grabgojek-cs-berlaku-naik-rp-250-

https://databoks.katadata.co.id/datapublish/2020/11/11/grab-dan-gojek-layanan-transportasionline-paling-sering-digunakan-masyarakat

https://id.wikipedia.org/wiki/Gojek

https://www.gojek.com/blog/gojek/goscreen/ 